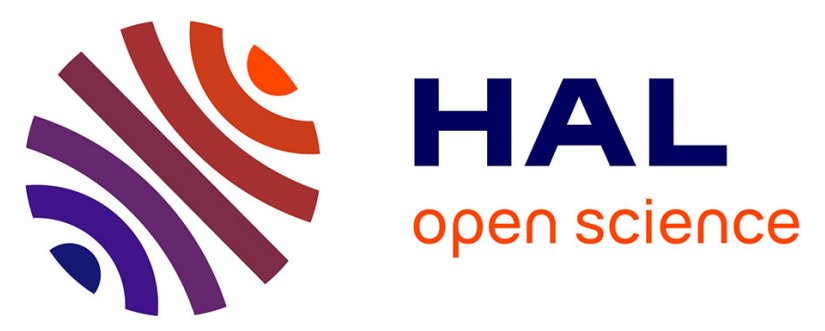

\title{
Improvement of the versatility of an arabinofuranosidase against galactofuranose for the synthesis of galactofuranoconjugates
}

\author{
Quentin Pavic, Aline Pillot, Olivier Tasseau, Laurent Legentil, Sylvain \\ Tranchimand
}

\section{To cite this version:}

Quentin Pavic, Aline Pillot, Olivier Tasseau, Laurent Legentil, Sylvain Tranchimand. Improvement of the versatility of an arabinofuranosidase against galactofuranose for the synthesis of galactofuranoconjugates. Organic \& Biomolecular Chemistry, 2019, 17 (28), pp.6799-6808. 10.1039/c9ob01162e . hal-02179650

\section{HAL Id: hal-02179650 \\ https://hal-univ-rennes1.archives-ouvertes.fr/hal-02179650}

Submitted on 16 Jul 2019

HAL is a multi-disciplinary open access archive for the deposit and dissemination of scientific research documents, whether they are published or not. The documents may come from teaching and research institutions in France or abroad, or from public or private research centers.
L'archive ouverte pluridisciplinaire HAL, est destinée au dépôt et à la diffusion de documents scientifiques de niveau recherche, publiés ou non, émanant des établissements d'enseignement et de recherche français ou étrangers, des laboratoires publics ou privés. 


\title{
Improvement of the versatility of an arabinofuranosidase against galactofuranose for the synthesis of galactofuranoconjugates
}

\author{
Quentin Pavic, ${ }^{a}$ Aline Pillot, ${ }^{a}$ Olivier Tasseau, ${ }^{a}$ Laurent Legentil ${ }^{a}$ and Sylvain Tranchimand $*^{a}$
}

\begin{abstract}
Galactofuranoconjugates are rare compounds with interesting biological properties. Their syntheses by traditional approaches are however tedious. Glycosidases are nowadays often used to simplify such synthesis but no galactofuranosidase has been described yet for the synthesis of galactofuranoconjugates. Interestingly CtAraf51, an $\alpha$-L-arabinofuranosidase from Ruminiclostridium thermocellum, is able to use aryl- or alkyl- $\beta$-Dgalactofuranosides as substrate but with very low efficiency. To allow its use as a synthesis tool, we decided to improve the efficiency of this enzyme toward these non-natural substrates. First, we identified three residues that can contribute to unfavorable interactions with the $p$-nitrophenyl- $\beta$-Dgalactofuranoside. After mutagenesis, two mutants have shown a catalytic efficiency four and threefold higher than the wild type respectively. These two mutants were then evaluated in transglycosylation reaction using ethanol as a model acceptor substrate. In these conditions one mutant was much more efficient: the $50 \%$ conversion was reached ten times faster than with the WT. Finally both mutants were converted into thioglycoligases: in thioligation reaction, the reaction was two times faster than with the E173A single mutant, and in acylation reaction a fourfold increase in the initial velocity was found. The synthetic potential of the resulting mutants to synthesize various $O$-, $S$ - and acyl galactofuranoconjugates was further evaluated and yields up to $82 \%$ were obtained for the synthesis of ethyl- or thiophenyl galactofuranosides and methoxybenzoic galactofuranose.
\end{abstract}

\section{Introduction}

Hexoses in their furanose form are less stable than their pyranose counterpart from a thermodynamics point of view, ${ }^{1}$ the first consequence being the low occurrences in nature of their polymeric or glycosidic derivatives. For instance, $\beta-D-$ galactofuranose has only been reported in a limited number of microorganism families, and has never been observed in mammals. ${ }^{2}$ Interestingly, among those microorganisms, several are pathogenic, like some Mycobacteria (Mycobacterium tuberculosis), ${ }^{3}$ Trypanosoma (Trypanosoma cruzi), ${ }^{4}$ Leishmania (Leishmania donovani) ${ }^{5}$ or Aspergillus (Aspergillus fumigatus). ${ }^{6}$ Then the galactofuranose moiety appears to be an interesting target in the development of drugs against those pathogenic microorganisms. This assumption has already been demonstrated with the octyl- $\beta-D-$ galactofuranoside and a few derivatives of this compound, showing activities against mycobacteria and leishmania, but no adverse effects on mammal cells. ${ }^{7-9}$

\footnotetext{
a. Univ Rennes, Ecole Nationale Supérieure de Chimie de Rennes, CNRS, ISCR - UMR 6226, F-35000 Rennes, France. E-mail: sylvain.tranchimand@ensc-rennes.fr

+ Electronic Supplementary Information (ESI) available: $\left[{ }^{1} \mathrm{H}\right.$ and ${ }^{13} \mathrm{C}$ NMR, primer list, screening tables, NMR kinetics and docking experiments].
}

Octyl- $\beta$-D-galactofuranoside is relatively easy to synthesize $^{10}$ but due to the $O$-glycosidic linkage, its lifetime might be shorten by endogenous hydrolases arising from the target microorganisms. To overcome this limitation, the synthesis of new antiparasitic galactofuranosyl derivatives is needed, and other glycosidic linkages, like the $S$ - or the acyl one, are envisioned. However, their syntheses are much more tedious because of the unfavorable competition with the thermodynamically more stable pyranosyl isomers. ${ }^{9,} 11,12$ An interesting alternative would be to use a specific biocatalyst, able to convert an easy to obtain galactofuranosyl donor into compounds of interest in a single step, simply through reactions with the desired acceptors. This enzymatic strategy would avoid any isomerisation into pyranose and generally lead to a single anomer. Two families of enzymes can possibly show such kind of activity: galactofuranosyl transferases and galactofuranosyl hydrolases. Several attempts have been done to use transferases as tools for organic synthesis, but due to the nature of the donor substrates, UDP-glycosides, compounds with very low stabilities and tricky synthesis, their use has always been limited to small scales. ${ }^{13}$ On the other side, hydrolases have been used extensively for such purposes, as their activities can easily be modulated to afford a wide variety of alkyl glycosides by transglycosylation or 
thioligation. ${ }^{14}$ Unfortunately, hydrolases with specificity toward the galactofuranose moiety are rare. This enzymatic activity has been observed and monitored in various microorganism species for decades, ${ }^{15-18}$ but proteins responsible for these activities were never isolated until recently. ${ }^{19,20}$ Even so, the recently cloned galactofuranosidases have quite low activities ( $K_{M}$ values of 4.4-6.8 mM, no reported $k_{\text {cat }}$ values) and have only been characterized in hydrolysis mode of either the natural Aspergillus fumigatus galactomannan or the non-natural substrate $p$-nitrophenyl- $\beta$ D-galactofuranoside 1 so their potential as a synthesis tool has not been demonstrated. Fortunately, $\beta$-D-galactofuranose and $\alpha$-L-arabinofuranose are closely related glycosides, their only difference being an additional hydroxymethyl group on the $C-5$ of galactofuranose compared to arabinofuranose (Figure 1), so we supposed that enzymes acting on L-arabinofuranose might also have an activity against D-galactofuranose, or at least could be a starting point for the development of a biocatalyst using galactofuranose as substrate.

Unlike $\beta$-D-galactofuranosidases, $\alpha$-L-arabinofuranosidases are widely represented in nature, and several of them have been cloned, heterologously expressed in E. coli and well characterized. ${ }^{21}$ For instance CtAraf51, a thermostable $\alpha-\mathrm{L}-$ arabinofuranosidase from Ruminiclostridium thermocellum, is a very versatile enzyme that has already been used as a biocatalyst for the synthesis of various alkyl arabinosides ${ }^{22}$ and oligoarabinosides ${ }^{23}$ and in a mutated form for the synthesis of thioaryl arabinofuranosides ${ }^{24}$ and acyl arabinofuranoses ${ }^{25}$ using as the donors either $p$-nitrophenyl- $\alpha$-L-arabinofuranoside 2 for transglycosylation reactions or 2'-benzimidazolyl 1-thio$\alpha$-L-arabinofuranoside 3 for thioligation and acylation (Scheme 1). Furthermore, it has also already been shown that this enzyme is able to use galactofuranoses as donor substrates, but with very low efficiency $\left(k_{c a t} / K_{M}=456 \mathrm{~s}^{-1} \cdot \mathrm{M}^{-1}\right.$ for the hydrolysis of $p$-nitrophenyl- $\beta$-D-galactofuranoside $\mathbf{1}$ compared to the $1.6 \times 10^{5} \mathrm{~s}^{-1} . \mathrm{M}^{-1}$ for the hydrolysis of 2$) .{ }^{26}$ Based on these previous results, we intended to greatly improve this enzyme CtAraf51 to get a performant tool for the biocatalyzed synthesis of galactofuranoconjugates. Molecular docking and dynamics were first carried out to directly compare the wildtype enzyme complexed with $\mathbf{1}$ and $\mathbf{2}$. This in silico approach highlighted a possible clash between the additional hydroxymethyl and some amino acids of the active site pocket. Subsequent protein engineering was performed and the resulting mutants were evaluated as potential catalysts for transglycosylation, acylation and thioligation of galactofuranose donors.

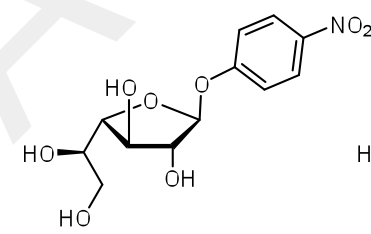

1

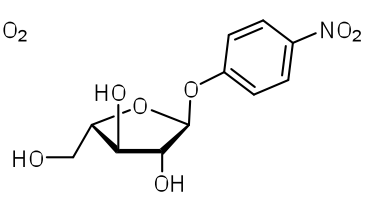

2
Figure 1. Structural homology of $p$-nitrophenyl- $\beta$-D-galactofuranoside 1 and $p$ nitrophenyl- $\alpha$-L-arabinofuranoside 2 , differing only by the $\mathrm{CH}_{2} \mathrm{OH}$ at position 5 .

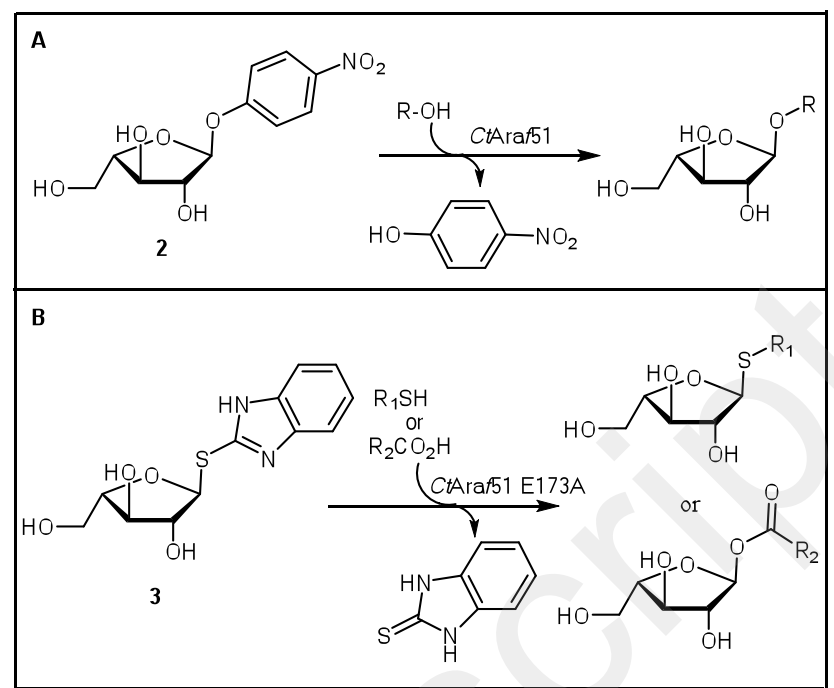

Scheme 1. CtAraf51 catalyzed reactions with activated arabinofuranosyl donors. A: Transglycosylation using $\mathbf{2}$ as the donor. B: Thioligation (acceptor=RSH)/acylation (acceptor $=\mathrm{RCO}_{2} \mathrm{H}$ ) using 2 '-benzimidazolyl 1-thio- $\alpha$-L-arabinofuranoside $\mathbf{3}$ as the donor.

\section{Results and Discussion}

Docking and molecular dynamics between CtAraf51 and 1.

A local docking, centered in the catalytic pocket, between 1 and the crystal structure of CtAraf51 (PDB ID: $2 \mathrm{C} 8 \mathrm{~N})^{27}$ has been performed using autodock vina ${ }^{28}$ by Yasara $^{29}$ and compared to the docking between the enzyme and its known substrate $\mathbf{2}$. When docked to the active site, $\mathbf{2}$ is stabilized by a hydrogen bonds network with E292, N172, E27, N72 and Q352 (S. I., Figure S1.A) as previously described by Davies et al. ${ }^{27}$ Conversely, after docking 1, very few hydrogen bonds were proposed (S. I., Figure S1.B), and the hydroxymethyl branched on $C-5$ fitted within an apolar region formed by residues L29, L319 and 1357 (Figure 2.A).

To confirm the role of this hydrophobic region, Molecular Dynamic (MD) simulations at $\mathrm{pH} 7$ in water were then performed. After a 10 ns MD, 2 stayed away from the hydrophobic pocket and only slight conformational changes were observed. On the contrary, for 1 the extra hydroxymethyl group shifts closer to the apolar residues L29, L319 and 1357 and an extra hydrogen bond between $\mathrm{OH}-6$ and E27 is found. The apolar environment tends to exert a steric strain on the ligand. Consequently the galactofuranose ring stretches and assumes a different positioning toward the nucleophilic residue E292 (Figure 2.B). In the complex between 2 and CtAraf51, the angle between the oxygen of the carboxylic side chain of E292 and the $\mathrm{C}-\mathrm{O}$ bond at the anomeric position $\left(\mathrm{O}_{292} \cdots \mathrm{C}-\mathrm{O}(p N \mathrm{NP})\right.$ angle $)$ is around $127^{\circ}$ and shifts to $66^{\circ}$ in the complex with 1. These changes can explain the great loss of either the affinity (repulsion between the hydroxyl and the hydrophobic pocket) and the reactivity of the enzyme (bad positioning between the nucleophilic residue and the anomeric carbon). To overcome these issues, we thus envisioned modifying the hydrophobic pocket residues in order either to loosen the pocket or to change the weak bonds network with 

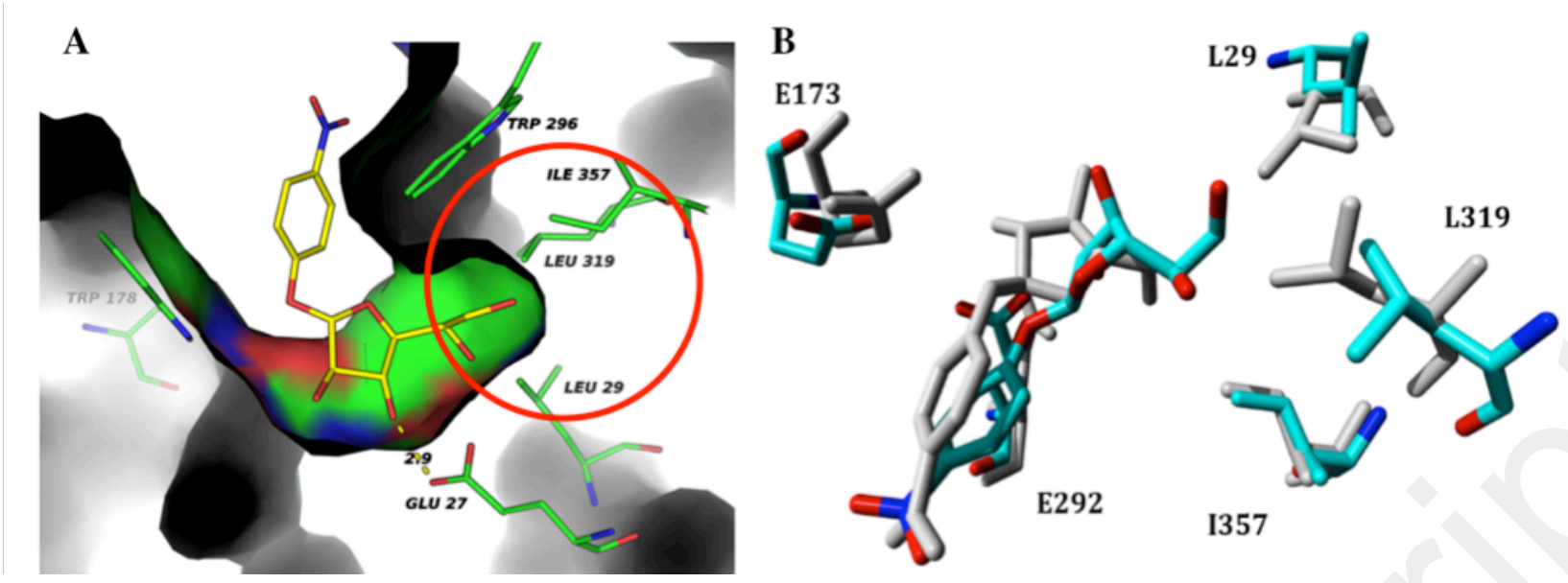

Figure 2. A: Docking experiment between CtAraf51 and 1. B: Superimposition of the complexes between CtAraf51 and either 1 (red/blue/cyan) or 2 (grey) after a $10 \mathrm{~ns}$ MD. The main active site residues are labeled.

the extra hydroxymethyl group, allowing stabilization of the substrate in the active site and/or repositioning toward the nucleophilic residue.

\section{Saturation mutagenesis at positions 29, 319 and 357 and} subsequent screening.

Saturation mutagenesis was then performed independently on the three positions 29,319 and 357 using the Agilent QuikChange Lightning site-directed mutagenesis kit according to the manufacturer instructions and primers listed in S. I. (Table S1). The plasmid DNA matrix was a previously described construction in pET28, encoding for a $N$-terminal $6 \mathrm{His}$ tagged CtAraf51. ${ }^{27}$ After a double transformation, first into TOP10 then into BL21(DE3) Star, several hundred isolated colonies were obtained, and 200 of them were picked up randomly and grown separately in liquid cultures to ensure statistically that $95 \%$ of the codons have been sampled. ${ }^{30}$

Production of the mutated enzymes were performed in the autoinducible medium $\mathrm{ZYP} 5052^{31}$ to ensure an optimal homogeneity in expression level between the different tubes. After cell lysis, galactofuranosyl hydrolase activity was evaluated over time in standardized conditions. The initial velocities were calculated and compared to those of strains expressing the wild type (WT) enzyme in the same conditions. Given that despite the homogenized expression conditions we used, the expression levels from strain to strain can vary a lot, for every bank we decided to sequence the best $20 \%$ of the entire bank (S. I., Figures S2A, B and C).
All the selected mutants above were then produced in large scale and purified to homogeneity on Ni-NTA columns. Then, the apparent kinetic parameters were measured with 1 as the substrate, at $\mathrm{pH} 7$ and $25^{\circ} \mathrm{C}$ (Table 1 ). In these conditions, hydrolysis of $\mathbf{1}$ without enzyme was not significant even after $24 \mathrm{~h}$.

The results were very different from one position to the other. On one hand, at position 357, none of the mutants showed an improved activity toward the galactofuranose moiety. On the other hand, very interesting results were obtained with the mutagenesis at positions 29 and 319.

At the position 319 , six interesting mutants with higher reaction rate than the $\mathrm{WT}$ in the screening conditions were identified: L319I, L319V, L319T, L319E, L319G and L319N. They all showed a strongly reduced apparent $K_{M}$ toward 1 compared to the WT, up to a 20 -fold decrease, meaning an enhanced affinity for this substrate. However their turnover numbers are reduced. In the case of the position 29, four mutants, with mutations either polar or apolar, have reaction rates comparable to the WT: the L29V, L29T, L29A and L29S. Nevertheless, their catalytic parameters were different from the L319 mutants: their $K_{M}$ were only slightly reduced, but those mutants showed $k_{\text {cat }}$ values at the same level or higher than the WT. For both positions, these improvements could be explained either by slight modifications of the empty volume around the $\mathrm{CH}_{2} \mathrm{OH}$ (mostly arising from apolar residues) or a reorganized hydrogen bond network (due to polar residue), affecting the stabilization of the substrate in the active site and its positioning toward the catalytic residues.

\begin{tabular}{|c|c|c|c|c|c|c|c|}
\hline  & WT & L319I & L319V & L319T & L319E & L319G & L319N \\
\hline$K_{M(\text { app })}(\mathrm{mM})$ & $40 \pm 8$ & $3.0 \pm 0.2$ & $3.4 \pm 0.1$ & $6.3 \pm 0.2$ & $3.4 \pm 0.1$ & $7.3 \pm 0.4$ & $2.4 \pm 0.2$ \\
\hline$k_{\text {cat (app) }}\left(\mathrm{s}^{-1}\right)$ & $20 \pm 4$ & $2.13 \pm 0.04$ & $7.6 \pm 0.1$ & $7.7 \pm 0.2$ & $3.32 \pm 0.04$ & $5.8 \pm 0.2$ & $2.2 \pm 0.1$ \\
\hline$k_{\text {cat }} / K_{M}\left(\mathrm{~s}^{-1} \mathrm{M}^{-1}\right)$ & 500 & 710 & 2235 & 1222 & 976 & 795 & 933 \\
\hline & L29V & L29T & L29A & L29S & I357V & I357L & \\
\hline$K_{M(\text { app })}(\mathrm{mM})$ & $19 \pm 3$ & $16 \pm 2$ & $30 \pm 5$ & $26 \pm 6$ & $70 \pm 50$ & $12 \pm 2$ & \\
\hline$k_{\text {cat(app) }}\left(\mathrm{s}^{-1}\right)$ & $31 \pm 3$ & $26 \pm 2$ & $41 \pm 5$ & $17 \pm 4$ & $2 \pm 1$ & $3.6 \pm 0.3$ & \\
\hline$k_{\text {cat }} / K_{M}\left(\mathrm{~s}^{-1} \mathrm{M}^{-1}\right)$ & 1632 & 1625 & 1367 & 654 & 29 & 300 & \\
\hline
\end{tabular}


Finally, over the different selected mutants, three of them showed at least a threefold increase in catalytic efficiency: L319V, L29V and L29T. As the mutants L29V and L29T have very comparable apparent kinetic parameters, only the mutants L319V and L29V were kept for further evaluations. Based on these results, the plasmid encoding for the double mutant L319V,L29V was also constructed but we never succeeded in expressing the folded protein.

\section{Molecular dynamics studies of the best mutants L319V and L29V with compound 1.}

In order to rationalize the results related to the best mutants L319V and L29V, in silico mutagenesis of CtAraf51 on these positions followed by local docking of $\mathbf{1}$ in the catalytic pocket was performed. Then, the conformational constraints of the ligand within the pockets were explored by molecular dynamics. First, it was observed for both mutants that the catalytic pocket presents a larger entrance of the -1 sub-site compared to the wild type CtAraf51, facilitating the accommodation of the ligand (S. I., Figure S3). As the mutated valine is shorter than the wild type leucine, the steric constraint is probably reduced thus explaining the improved efficiency of both mutants.

After a $10 \mathrm{~ns} \mathrm{MD}$, the complex with the mutant L319V is characterized by 1 caged in the active site between W178 and Y244. Interestingly, a strong hydrogen bond network is reestablished with residues E292, E27 and N72 (S. I., Figure S4A). These considerations can explain the strong decrease of $K_{M}$. However this stronger interaction between the substrate and the enzyme induces the same distortions of the furanose ring as with the wild type enzyme, with an upward shift of the endocyclic oxygen and a $\mathrm{O}_{292} \cdots \mathrm{C}-\mathrm{O}(p N \mathrm{~N})$ angle around $70^{\circ}$ (Figure 3.A). It explains probably, the very poor measured $k_{\text {cat }}$ value.

In the case of L29V mutant, MD confirms a different fitting of 1 within the active site (Figure 3.B). A hydrogen bond network around the $\mathrm{OH}-3$ is reestablished with N72 and E27 like in the complex between CtAraf51 WT and 2 (S. I., Figure S4B). However the dynamic suggests a deep insertion of $\mathrm{OH}-6$ between the identified apolar residues resulting in a steric clash and consistent with a relatively high $K_{M}$ value. Interestingly there is a rotation of the furanose ring compared to the complex between 1 and the WT enzyme (Figure 3.B), recovering a favorable $\mathrm{O}_{292}$ '. C$\mathrm{O}(p N \mathrm{~N})$ angle $\left(120^{\circ}\right)$. This positioning of the ligand, close to the one found for $\mathbf{2}$ in the WT enzyme (Figure 2B), could explain the increased turn-over (Table 1, L29V vs WT).

\section{Transglycosylation reactions using the best mutants as biocatalysts.}

To favor the transglycosylation with glycosidases, very high concentrations of donor and acceptor substrates were used. In these conditions, the apparent Michaelis-Menten parameters measured so far are not representative of the
A

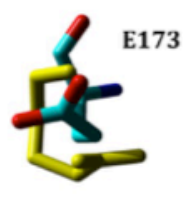

L29
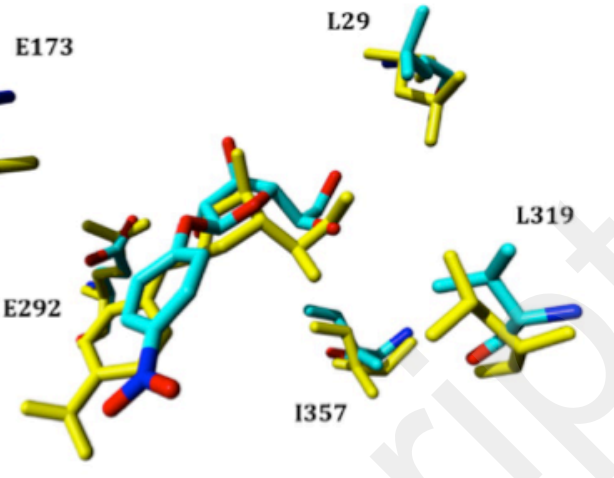

B

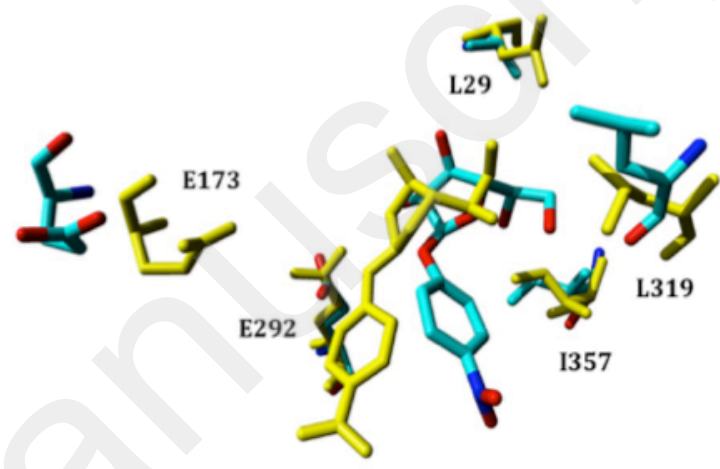

Figure 3. Superimposition of the complexes between 1 and CtAraf51 WT (yellow) or CtAraf51 mutants (red/blue/cyan) (A: L319V; B: L29V).

complete reaction system (hydrolysis, autocondensation, transglycosylation and secondary hydrolysis) and the selected mutants have to be evaluated under these specific conditions. As a model reaction, we used the transglycosylation of a nitrophenyl donor and ethanol as the acceptor (Scheme 2). The reaction settings $(\mathrm{pH} 7$, phosphate buffer, $15 \mathrm{mM}$ of donor and $3.8 \mathrm{M}$ of acceptor) were adapted from previous results of transglycosylation between an arabinofuranosyl donor and ethanol catalyzed by CtAraf $51 \mathrm{WT} .^{22}$ The reactions were followed at $25^{\circ} \mathrm{C}$ over time by ${ }^{1} \mathrm{H}$ NMR using isolated characteristic peaks for

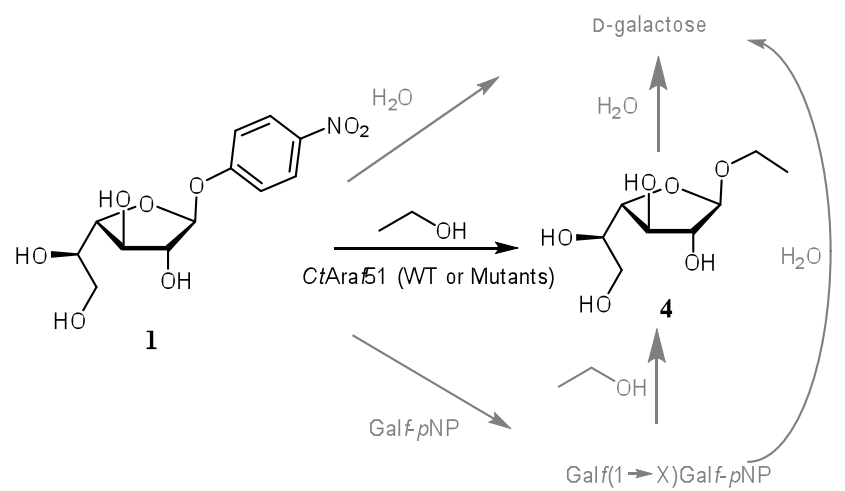

Scheme 2. Model reaction system for transglycosylation with ethanol as the acceptor substrate. Black: main expected transglycosylation reaction. Grey: side reactions (autocondensation, hydrolysis, secondary hydrolysis and transglycosylation) 
every compound $(H-1$ proton for 1 , i.e. a doublet at 5.7 ppm, and $H-2$ proton for ethyl $\beta$-D-galactofuranoside 4 , i.e. a doublet of doublet at $3.9 \mathrm{ppm}$ ). The kinetics of the standardized reactions using an equal quantity of the WT enzyme or the mutants L319V and L29V are summarized in Figure 4, and the NMR traces are reported in S. I. (Figures S5A, B and C). We can first observe that the mutants have retained the ability to catalyze transglycosylation. In these conditions, the WT and the mutant L319V have very similar profiles, except at the very end of the reaction where the WT conversion rate decreases faster. This observation is in agreement with the $K_{M}$ value for the donor substrate observed above: as the $K_{M}$ is much lower for this mutant, with a comparable initial velocity, when the donor concentration decreases, the conversion rate will become higher for the mutant compared to the WT.

Finally, the most interesting point in this experiment is the conversion rate of the mutant L29V: the initial velocity is more than 5 fold higher than those of the WT, and this difference increases even more during the time course of the reaction, the duration to reach $50 \%$ of conversion being 10 fold higher with the WT than with this mutant. As we can reach $90 \%$ of conversion with this mutant, it appears very promising as a tool for the biocatalyzed synthesis of alkyl galactofuranosides. To evaluate the synthetic potential of this L29V mutant in transglycosylation, a preparativescale synthesis was performed. Gratifyingly it gives the corresponding compound 4 as a single anomer with $81 \%$ isolated yield.

\section{Thioglycosylation and acylation of galactofuranose using the thioglycoligase mutants.}

To extend the use of these enzymes as synthesis tools, the best two mutants, L319V and L29V, were converted into thioglycoligases by the replacement of the glutamate at position 173 by an alanine according to a previously described mutagenesis on the WT. ${ }^{24}$ The resulting double mutants were evaluated for their abilities to catalyze the synthesis of thiogalactofuranosides and also for their abilities to catalyze the synthesis of acyl galactofuranoses, a recently described catalytic activity of thioglycoligases ${ }^{25}$



Figure 4. Transglycosylation reaction kinetics between 1 and ethanol catalyzed by CtAraf51 WT or the mutants L319V and L29V. The reaction conditions were standardized as follow: $15 \mathrm{mM}$ of donor substrate, $3.8 \mathrm{M}$ of acceptor, $2.7 \mu \mathrm{M}$ of enzyme, $\mathrm{pH} 7$ and $25^{\circ} \mathrm{C}$.

(Scheme 3). The donor substrate 2'-benzimidazolyl 1-thio- $\beta$ D-galactofuranoside $\mathbf{5}$ was chosen by analogy with previous results about the biocatalyzed thioligation of arabinofuranoses. The reactions between this donor and thiophenol or $p$-methoxybenzoic acid were followed over time by ${ }^{1} \mathrm{H}$ NMR using isolated characteristic peaks for every compound $(H-1$ proton for 5 , i.e. a doublet at 5.7 ppm, $\mathrm{H}$-1 proton for $p$-methoxybenzoyl $\beta$-D-galactofuranose 6 , i.e. a singlet at $6.1 \mathrm{ppm}$ and $\mathrm{H}-1$ proton for phenyl thio- $\beta$ D-galactofuranoside 7, i.e. a doublet at $5.2 \mathrm{ppm}$ ). Acylation kinetics in standardized conditions $(4.8 \mathrm{mM}$ of donor substrate, $19.4 \mathrm{mM}$ of acceptor, $2.7 \mu \mathrm{M}$ of enzyme, $\mathrm{pH} 6$ and $25^{\circ} \mathrm{C}$ ) are shown in Figure 5 and the NMR traces are reported in S. I. (Figures S6A, B and C). In these experiments, the two mutants have a very similar behavior and show a great improvement of the velocity of the reaction: the initial velocity is increased by a 2.5 -fold with both of the double mutants when compared to the E173A mutant, and the conversion rate decreases more slowly. Indeed to reach $50 \%$ of conversion the duration is reduced by a fourfold.

Unlike transglycosylation, the mutation L319V appears interesting. As the initial donor concentration is much lower



Scheme 3. Mechanism of thioligation and acylation reactions of $\mathbf{5}$ using either thiophenol or $p$-methoxybenzoic acid as acceptor substrates respectively. 


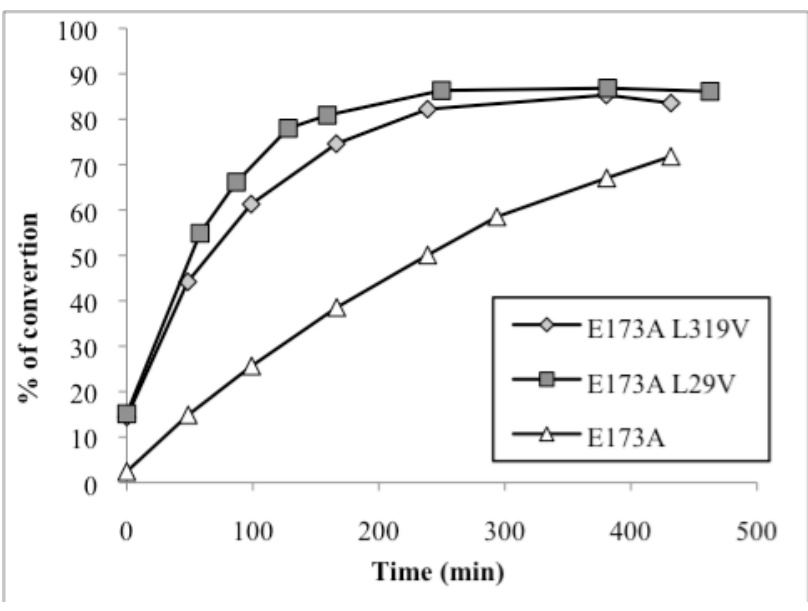

Figure 5. Acylation reaction between the donor $\mathbf{5}$ and $p$-methoxybenzoic acid catalyzed by CtAraf51 E173A reference mutant and the double mutants L319V E173A and L29V E173A. The reaction conditions were standardized as follow: $4.8 \mathrm{mM}$ of donor substrate, $19.4 \mathrm{mM}$ of acceptor, $2.7 \mu \mathrm{M}$ of enzyme, $\mathrm{pH} 6$ and $25^{\circ} \mathrm{C}$

(4.8 $\mathrm{mM}$ instead of $15 \mathrm{mM}$ ), the contribution of the affinity becomes higher in the overall efficiency of the reaction. Concerning the L29V mutation, the increased efficiency is a bit smaller than in transglycosylation conditions for the same reason. This mutation had a lower impact on the affinity but had a positive influence on the turn over. The gain becomes then lower with decreasing substrate concentration, even if a fourfold increase in the reaction rate remains very interesting.

Thioligation kinetics in standardized conditions (3.84 $\mathrm{mM}$ of donor substrate, $15.3 \mathrm{mM}$ of acceptor, $2.7 \mu \mathrm{M}$ of enzyme, $\mathrm{pH} 7$ and $25^{\circ} \mathrm{C}$ ) are shown in Figure 6 and the corresponding NMR traces are reported in S. I. (Figures S7A, $B$ and $C$ ). The two double mutants behave again very similarly, with an initial velocity higher than those of the E173A mutant, but less than a twofold. The shapes of the curves of the double mutants are also surprising: the

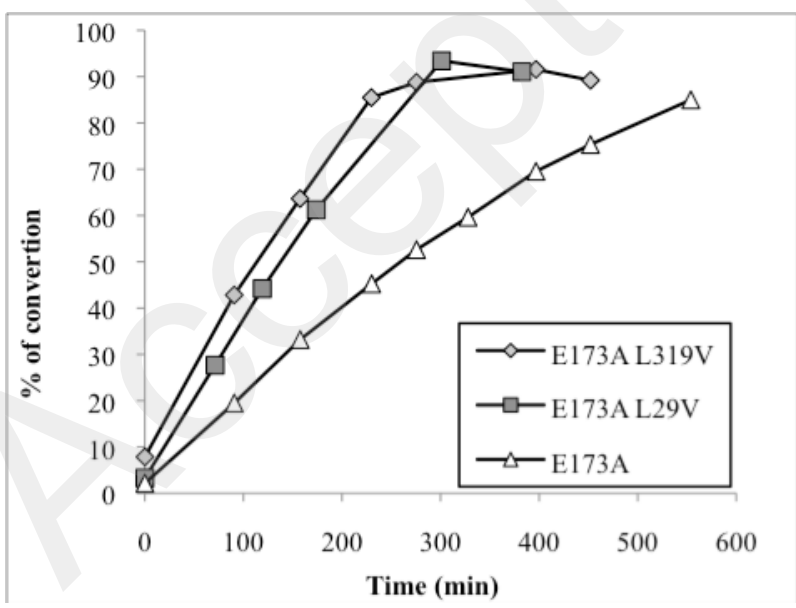

Figure 6. Thioligation reaction between the donor $\mathbf{5}$ and thiophenol catalyzed by CtAraf51 E173A reference mutant and the double mutants L319V E173A and L29V E173A. The reaction conditions were standardized as follow: $3.8 \mathrm{mM}$ of donor substrate, $15.3 \mathrm{mM}$ of acceptor, $2.7 \mathrm{uM}$ of enzyme, $\mathrm{pH} 7$ and $25^{\circ} \mathrm{C}$. conversion rates remains almost linear during all the time course of the experiment, until the complete consumption of the donor substrate. This can be explained according to the mechanism of the reaction (Scheme 3).

Indeed the thioligation occurs via two half-reactions with their own kinetic constants $k_{1}$ and $k_{2}$, first formation of a glycosyl-enzyme intermediate and then attack of the nucleophile. The $k_{\text {cat }}$ apparent values we measured are then related to both $k_{1}$ and $k_{2}\left(k_{\text {cat }}=k_{1} k_{2} /\left(k_{1}+k_{2}\right)\right)$. If the limiting step was the first half-reaction $\left(k_{1}<<k_{2} ; k_{c a t} \approx k_{1}\right)$, we should have obtained curves with very similar shapes in the acylation and thioligation reactions, as this first halfreaction is exactly the same in both cases. This means that in the case of the thioligation, $k_{2}$ contributes more to the apparent $k_{\text {cat }}$ value. Considering that mutations in the hydrophobic pocket of the donor sub-site might essentially alter $k_{1}$, in this case, improvements of $k_{1}$ have a weaker overall impact on $k_{\text {cat }}$ explaining why the conversion rate is only increased by a twofold here with the double mutants instead of fourfold in acylation.

Finally both acylation and thioligation reactions were performed on a preparative scale: with the same donor $\mathbf{5}$, compounds 6 and $\mathbf{7}$ were obtained with gratifying isolated yields of $65 \%$ and $82 \%$ respectively.

\section{Conclusions}

At the starting point of this study, we identified in the $\alpha$ L-arabinofuranosidase CtAraf51 from Ruminiclostridium thermocellum a hydrophobic pocket made of three aminoacids L29, L319 and 1357, that might have been involved in the low activity toward galactofuranose derivatives compared to the natural activity of this enzyme toward arabinofuranoses. Docking and MD confirm the weaker stabilization of the substrate and the resulting unfavorable angle between the nucleophilic E292 carboxylate and the leaving group. Saturation mutageneses were performed on the three positions and the two mutants CtAraf51 L319V and L29V have shown the best improvements of the catalytic efficiency. Molecular modeling and experimental data confirm a different accommodation of the substrate within the binding pocket. The consequence is that in synthesis conditions, i.e. with high substrate concentrations, the mutant that is finally the most interesting is the L29V: the transglycosylation reaction time is reduced by a tenfold with an equal amount of enzyme, and after a second mutation to convert this enzyme into a thioglycoligase, the reaction time for acylation or thioligation are also reduced by a fourfold and a twofold respectively when compared to the enzyme derived from the WT. In addition, upscale preparations of the corresponding conjugates were performed with good yields. The advantage of this new process is the use of a biocatalyst known for its plasticity in reactivity and toward acceptor substrates. Thanks to a single-point mutation, we have turned this enzyme into a performant tool dedicated 
to the synthesis of various biologically relevant galactofuranoconjugates.

\section{Experimental Section}

\section{Chemicals}

All chemicals were purchased from Sigma Aldrich, Fisher Scientific, Alfa Aesar or VWR International unless otherwise stated at the highest quality level and were used without further purifications. 4-nitrophenyl- $\beta$-D-galactofuranoside 1 and 4-nitrophenyl- $\alpha$-L-arabinofuranoside $\mathbf{2}$ were purchased from Carbosynth Limited. 2'-benzimidazolyl 1-thio- $\beta$-Dgalactofuranoside 5 and 2 '-benzimidazolyl 1-thio- $\alpha$-Larabinofuranoside $\mathbf{3}$ were synthesized as previously described. ${ }^{32,33}$

\section{Expression and purification of enzymes.}

Escherichia coli strain BL21(DE3) Star cells (Invitrogen) transformed with the recombinant plasmid YsbI-LIC-pET28a bearing the CtAraf51 encoding sequence (kindly provided by Prof G. Davies, University of York, U.K.) ${ }^{27}$ were grown on Luria-Bertani (LB) broth plates containing kanamycin (50 $\mu \mathrm{g} / \mathrm{mL}$ ) (LBK). The gene encodes for a $\mathrm{N}$-terminus $6 \mathrm{His}$ tagged protein. A single colony was used to inoculate a preculture (10 mL LBK, $37{ }^{\circ} \mathrm{C}, 250 \mathrm{RPM}$, overnight). Autoinducing medium ZYP- $5052^{31}$ containing $400 \mu \mathrm{g} / \mathrm{mL}$ of kanamycin was inoculated with a $1 \%$ dilution of the later pre-culture. Cells were grown for $72 \mathrm{~h}\left(25^{\circ} \mathrm{C}, 250 \mathrm{rpm}\right)$. The cells were harvested by centrifugation $(3000 \mathrm{~g}, 30 \mathrm{~min}$, $\left.4^{\circ} \mathrm{C}\right)$, the supernatant was removed, and the pellet was resuspended in the lysis buffer $\mathrm{pH} 7(50 \mathrm{mM}$ phosphate, 10 $\mathrm{mM}$ imidazole $; 10 \%$ of the culture volume). The cells were disrupted using a Microfluidics M110P apparatus (interaction chamber G10Z $67 \mu \mathrm{m}$, working pressure: 20000 psi, the suspension is treated twice). Cell debris was removed by centrifugation $\left(13000 \mathrm{~g}, 30 \mathrm{~min}, 4^{\circ} \mathrm{C}\right)$ and the protein was purified on HisTrap HP affinity column (GE lifescience, loaded with $\mathrm{Ni}$ ) according to the manufacturer's procedure (imidazole gradient from 10 to $500 \mathrm{mM}$ ). Imidazole concentration was reduced by a $10^{4}$-fold by ultrafiltration using Amicon centrifugal filter units (Ultracel $10 \mathrm{~K}$, Millipore) according to the manufacturer's procedure. Protein concentrations were determined by Bradford protein assays, using commercial reagent (multiwell plate assay procedure, Sigma-Aldrich) and following the manufacturer's procedure. Enzyme purity was controlled by SDS-PAGE gel electrophoresis after Coomassie staining. All the different CtAraf51 mutants were produced and purified according to the same procedure.

\section{Site-directed Mutagenesis}

Site-directed saturation and point mutagenesis were performed using QuikChange Lightning Site-Directed Mutagenesis kit (Agilent) and plasmid Ysbl-LIC-pET28a or plasmids resulting from a first round of mutagenesis as DNA template, according to the manufacturer's procedure. The different primers used for mutagenesis are listed in Table S1 in Supplementary data. Mutagenesis raw reactions were used directly to transform One Shot ${ }^{\mathrm{TM}}$ TOP10 Chemically Competent E. Coli cells (ThermoFischer) according to the manufacturer's instructions. The resulting suspensions were spread on LB/kanamycin $(50 \mu \mathrm{g} / \mathrm{mL})$ plates and incubated at $37^{\circ} \mathrm{C}$ overnight.

For point mutagenesis, a single colony was used to inoculate $5 \mathrm{~mL}$ of LB/kanamycin $(50 \mu \mathrm{g} / \mathrm{mL})$ liquid medium, and the culture was incubated overnight $\left(37^{\circ} \mathrm{C}, 250 \mathrm{rpm}\right)$. The plasmids were extracted using StrataPrep Plasmid Miniprep Kit (Agilent) according to the manufacturer's procedure. DNA sequences were controlled by Sanger sequencing (GATC Biotech AG, Konstanz, Germany) and the plasmids were subsequently transformed into One Shot BL21 Star (DE3) chemically competent E. coli cells (ThermoFischer) according to the manufacturer's procedure to afford the expression strains.

For saturation mutagenesis, plates containing at least 200 colonies were washed with $5 \mathrm{~mL}$ of LB/kanamycin (50 $\mu \mathrm{g} / \mathrm{mL}$ ) liquid medium, and the washing suspensions were incubated overnight $\left(37^{\circ} \mathrm{C}, 250 \mathrm{rpm}\right)$. Plasmids were extracted as above and also transformed into One Shot BL21 Star (DE3) chemically competent E. coli cells (ThermoFischer). Transformation suspensions were spread on $\mathrm{LB} /$ kanamycin $(50 \mu \mathrm{g} / \mathrm{mL})$ plates to afford isolated colonies bearing individual mutations. DNA sequences of the selected mutants were analyzed after plasmid miniprep and Sanger sequencing as above.

\section{Galactofuranosyl hydrolase activity screening}

For every saturation site-directed mutagenesis, 192 isolated colonies were randomly picked up to inoculate individual cultures $(1 \mathrm{~mL}$ of $\mathrm{LB} /$ kanamycin $(50 \mu \mathrm{g} / \mathrm{mL})$ in $5 \mathrm{~mL}$ culture tubes). Cultures were incubated overnight $\left(37^{\circ} \mathrm{C}, 250 \mathrm{rpm}\right)$. $1 \mu \mathrm{L}$ of the resulting saturated cultures were subsequently used to inoculate $500 \mu \mathrm{L}$ of autoinduction media ZYP- $5052^{31}$ containing $400 \mu \mathrm{g} / \mathrm{mL}$ of kanamycin, in $5 \mathrm{~mL}$ culture tube. Cultures were incubated $72 \mathrm{~h}\left(25^{\circ} \mathrm{C}, 250 \mathrm{rpm}\right)$, then centrifuged $\left(16000 \mathrm{~g}, 5 \mathrm{~min}, 4^{\circ} \mathrm{C}\right)$. Supernatants were removed and cell pellets resuspended in $200 \mu \mathrm{L}$ of lysis buffer (phosphate buffer $50 \mathrm{mM}, \mathrm{pH} 7.2,1 \mathrm{mg} / \mathrm{mL}$ of lysozyme). Incubation/freezing cycles $\left(30 \mathrm{~min}\right.$ at $37^{\circ} \mathrm{C}$ then $30 \mathrm{~min}$ at $-80^{\circ} \mathrm{C}$ ) were applied twice to the suspensions. A further $1 \mathrm{~h}$ incubation at $37^{\circ} \mathrm{C}$ was finally applied before centrifugation $\left(16000 \mathrm{~g}, 15 \mathrm{~min}, 4^{\circ} \mathrm{C}\right)$. Supernatants containing the enzymes of interest were transferred into individual wells of two 96 well plates.

Activities were evaluated by measurement of compound 1 hydrolysis overtime at $405 \mathrm{~nm}$ according to the following procedure: to substrate solution $(200 \mu \mathrm{L}, 1 \mathrm{mM}$ in $50 \mathrm{mM}$ phosphate buffer $\mathrm{pH}$ 7) in 96 well plates were added $10 \mu \mathrm{L}$ of lysates (after a 20 fold dilution) and the increase in absorbance at $405 \mathrm{~nm}$ is followed over $30 \mathrm{~min}$ at $25^{\circ} \mathrm{C}$ with 
a microplate reader (PowerWave XS microplate spetrophotometer, Biotek).

\section{Kinetic parameters evaluation}

For Michaelis-Menten analysis, enzymatic activities were assayed in triplicate in a $500 \mu \mathrm{L}$ quartz cell (width $1 \mathrm{~cm}$ ) at $25^{\circ} \mathrm{C}$ in phosphate buffer $50 \mathrm{mM}, \mathrm{pH}$. The initial velocities were quantified based on the release of $p$-nitrophenolate $\left(\varepsilon_{405}=9259 \mathrm{M}^{-1} \mathrm{~cm}^{-1}\right) \cdot p \mathrm{NP}$-glycosides concentration ranged from $20 \mu \mathrm{M}$ to $9 \mathrm{mM}$, and the enzyme concentrations used were between 60 and $600 \mathrm{nM}$. Kinetic parameters were determined using Prism 6 software (GraphPad).

\section{In silico calculation}

Docking and molecular dynamics were carried out via Yasara 16.4.6 interface. ${ }^{29}$ For the enzyme and mutants, geometrical optimization and energy minimization were performed by Restricted Hartree-Fock methods, AM1 with the force field YAMBER03, ${ }^{34}$ an AMBER version for Yasara. In periodic conditions, this global optimization was executed in aqueous environment (dielectric constant $\varepsilon=$ 80) adjusted at $\mathrm{pH}=7$, in cell including $5 \AA$ around all atoms of enzyme. Long range electrostatic interactions were calculated using Particule Mesh Ewald (PME) algorithm, requiring periodic boundary conditions in cell. A 12 A cut off was defined for Van der Waals and Coulomb interactions to calculate potential energy. ${ }^{35}$ The models of ligands were built using from Glycam-web. ${ }^{36}$ Improved optimizations were carried out using Gaussian v09 software with standard B3LYP functional combining to the $6-311+G * *$ basis set. $^{37-39}$ The $p$ NP glycofuranosides ligand was inserted into a 12 to $15 \AA$ cell centered on the binding site around E292 glutamate atom (g-COO) on the basis of L-Araf- $\alpha-(1,3)-D-$ Xylp fitting. ${ }^{27}$ Local docking studies were performed using both optimized enzyme or mutants and ligand by Autodock Vina. $^{39}$

In silico mutagenesis of residues $\mathrm{L} 319$ and $\mathrm{L} 29$ were performed using Yasara Structure unit. Each mutant was optimized and energy minimized with the YAMBERO3 force field $^{34}$ in the same conditions described above, before local docking.

The MD simulations were performed using the same force field in Yasara package dynamics, at $298 \mathrm{~K}$, in a simulation cell built around the CtAraf51 model subunit. ${ }^{40}$ The solvation cell was filled with water molecules according to a solvent density of $0.997 \mathrm{~g} / \mathrm{ml}$. All the atoms were surrounded by $5 \AA$ water molecules and the system charge was neutralized, using $\mathrm{NaCl}$ with $0.9 \%$ concentration to maintain the $\mathrm{pH}$ at 7.0 over the entire simulation period. The MD simulations were carried out for $10 \mathrm{~ns}$ in periodic boundary conditions at constant volume with multiple time-step $1,25 \mathrm{fs}$ to $5 \mathrm{fs}$. Long-range coulomb forces were calculated with a $10,5 \AA$ cut off using the Particle Mesh Ewald method. Preliminary energy minimization by steepest descent was done to remove severe bumps followed by simulated annealing minimizations at $298 \mathrm{~K}$ and velocities were scaled down every ten steps for a total time of $5 \mathrm{ps}$ in 500 steps and to a final temperature of $0 \mathrm{~K}$. Equilibration time and simulation trajectories were analyzed and visualized by Yasara analysis algorythms. Interaction energies, root mean square deviations (RMSD) of the backbone and root mean square fluctuations (RMSF) per-residue and binding energy enzyme-substrat were calculated by Yasara MD analysis tools and graphs of their evolutions for MD time were generated. The in silico binding energy between the WT and mutants and ligands 1 and $\mathbf{2}$ were compared and MD conformations with strongest binding energy were analyzed with regards with the minimal energy conformation.

\section{Transglycosylation reactions}

For transglycosylation reactions, $500 \mu \mathrm{L}$ of solution containing $2.5 \mathrm{mg}$ of $1(8 \mathrm{mmol}), 25 \%(\mathrm{v} / \mathrm{v})$ of ethanol and $100 \mu \mathrm{g}$ of enzyme (CtAraf51 WT or mutants L319V or L29V) in phosphate buffer ( $50 \mathrm{mM}, \mathrm{pH}$ 7) were prepared. $450 \mu \mathrm{L}$ were withdrawn and transferred into a NMR tube. $50 \mu \mathrm{L}$ of $\mathrm{D}_{2} \mathrm{O}$ were added and the reaction at $25^{\circ} \mathrm{C}$ was followed over time by ${ }^{1} \mathrm{H}$ NMR (water suppression experiment, 32 scan, internal standard for quantification: benzene in a capillary tube). Conversion rates were calculated using the integration of proton $\mathrm{H}-1$ (doublet, $5.7 \mathrm{ppm}$ ) for the donor substrate and $\mathrm{H}-2$ (doublet of doublet, $3.9 \mathrm{ppm}$ ) for ethyl $\beta$ D-galactofuranoside 4 standardized with the benzene peak at $7.3 \mathrm{ppm}$.

\section{Thioligation and acylation evaluation}

$1.5 \mathrm{~mL}$ of solutions containing donor 5 (3.8-4.8 mM, 1 eq) and acceptors (thiophenol or $p$-methoxybenzoic acid; 4 eq) were prepared in phosphate buffer $(50 \mathrm{mM}, \mathrm{pH}$ 7). After addition of enzyme (E173A mutants, single mutant or combined with mutations at positions 29 or 319; 0.18 $\mathrm{mg} / \mathrm{mL}$ final concentration), $10 \%(\mathrm{v} / \mathrm{v})$ of $\mathrm{D}_{2} \mathrm{O}$ were added and the reactions were followed over time by ${ }^{1} \mathrm{H} N M R$ (water suppression experiment, 32 scans). Anomeric protons are used to quantify the different species (donor $\mathbf{5}$ : doublet, $5.7 \mathrm{ppm}$; 1-O-methoxybenzoyl $\beta$-D-galactofuranose 6: singlet, $6.1 \mathrm{ppm}$; phenyl thio- $\beta$-D-galactofuranoside 7: singlet, $5.2 \mathrm{ppm}$ ).

\section{Preparative synthesis of the galactofuranoconjugates 4, 6 and 7}

Ethyl- $\beta$-D-galactofuranoside (4): To a solution of $\mathbf{1}$ (150 mg, $0,5 \mathrm{mmol})$ in a mixture of ethanol $(11.2 \mathrm{~mL})$ and $50 \mathrm{mM}$ phosphate buffer at $\mathrm{pH} 7(45 \mathrm{~mL})$ was added the CtAraf51 L29V enzyme solution $(680 \mu \mathrm{L}$ at $4 \mathrm{mg} / \mathrm{mL}$ in $50 \mathrm{mM}$ phosphate buffer $\mathrm{pH} 7$ ). After 3 hour of reaction, an NMR analysis confirmed the complete conversion of the donor. The crude mixture was freeze dried and purified on silica gel (Dichloromethane/MeOH 9:1) to yield the desired product 4 as a white powder with $81 \%$ yield $(86 \mathrm{mg}, 4.1$ mmol). ${ }^{1} \mathrm{H}$ NMR (400 MHz; DMSO- $\left.d_{6}\right) \delta=5.27\left(\mathrm{~d}, 1 \mathrm{H}, J_{\mathrm{OH}-2,2}\right.$ $=5.6 \mathrm{~Hz}, \mathrm{OH}-2), 5.05\left(\mathrm{~d}, 1 \mathrm{H}, J_{\mathrm{OH}-3,3}=5.6 \mathrm{~Hz}, \mathrm{OH}-3\right), 4.69$ (d, $\left.1 \mathrm{H}, J_{1,2}=2.5 \mathrm{~Hz}, \mathrm{H}-1\right), 4.55\left(\mathrm{~d}, 1 \mathrm{H}, J_{\mathrm{OH}-5,5}=6.2 \mathrm{~Hz}, \mathrm{OH}-5\right)$, 
$4.53\left(\mathrm{~d}, 1 \mathrm{H}, J_{\mathrm{OH}-6,6}=6.0 \mathrm{~Hz}, \mathrm{OH}-6\right), 3.82\left(\mathrm{dt}, 1 \mathrm{H}, J_{3,4}=7.5 \mathrm{~Hz}\right.$, $\left.J_{3, \mathrm{OH}-3}=J_{3,2}=5.6, \mathrm{H}-3\right), 3.74\left(\mathrm{dd}, 1 \mathrm{H}, J_{2, \mathrm{OH}-2}=J_{2,3}=5.6 \mathrm{~Hz}, J_{2,1}\right.$ $=2.5, \mathrm{H}-2$ ), 3.71 (dd, $1 \mathrm{H}, J_{4,3}=7.5 \mathrm{~Hz}, J_{4,5}=2.9, \mathrm{H}-4$ ), 3.62 (dq, $\left.1 \mathrm{H}, J_{\mathrm{OCH} 2 \mathrm{a}, \mathrm{OCH} 2 \mathrm{~b}}=9.7 \mathrm{~Hz}, J_{\mathrm{OCH} 2 \mathrm{a}, \mathrm{CH} 3}=7.1, \mathrm{OCH}_{2}\right), 3.47(\mathrm{~m}$, $1 \mathrm{H}, \mathrm{H}-5), 3.37\left(\mathrm{~m}, 3 \mathrm{H}, \mathrm{H}-6\right.$ and $\left.\mathrm{OCH}_{2}\right), 1.12\left(\mathrm{t}, 3 \mathrm{H}, \mathrm{J}_{\mathrm{CH} 3, \mathrm{CH} 2}=\right.$ $\left.7.1 \mathrm{~Hz}, \mathrm{CH}_{3}\right) .{ }^{13} \mathrm{C}$ NMR (100 MHz, DMSO- $\left.d_{6}\right) \delta=107.48(\mathrm{C}-1)$, 82.02 (C-2), 81.78 (C-4), 76.48 (C-3), 70.36 (C-5), 62.78 (C6), $62.33\left(\mathrm{CH}_{2}\right), 15.19\left(\mathrm{CH}_{3}\right)$. HRMS (ESI): $\mathrm{m} / z=231.0834$, calcd. for $\mathrm{C}_{8} \mathrm{H}_{16} \mathrm{O}_{6} \mathrm{Na}$ : 231.0845 .

1-O-(4'-methoxybenzoyl)- $\beta$-D-galactofuranose (6): $\quad A$ mixture of 4-methoxybenzoic acid (201 $\mathrm{mg}, 1.3 \mathrm{mmol}$ ) in phosphate buffer $(20 \mathrm{~mL}, 50 \mathrm{mM}, \mathrm{pH}=6)$ was prepared and $\mathrm{pH}$ was adjusted to 6 with $\mathrm{NaOH} 2 \mathrm{~N}$. The double mutant enzyme CtAraf51 E173A L319V $(800 \mu \mathrm{L}$ at $6 \mathrm{mg} / \mathrm{mL}$ in 50 $\mathrm{mM}$ phosphate buffer $\mathrm{pH}$ 7) and the donor 5 (100 mg, 0.35 $\mathrm{mmol})$ were then added. The mixture was stirred at room temperature for 16 hours. After freeze-drying, the mixture was purified by column chromatography on silica gel (dichloromethane/methanol 9:1) to yield the corresponding product 6 as a white solid with $65 \%$ yield $(65 \mathrm{mg}, 0.21$ mmol). ${ }^{1} \mathrm{H}$ NMR (400 MHz; DMSO- $\left.d_{6}\right) \delta=7.94(\mathrm{~d}, 2 \mathrm{H}, J=8.9$ $\left.\mathrm{Hz}, \mathrm{H}_{\text {arom }}\right), 7.07\left(\mathrm{~d}, 2 \mathrm{H}, J=8.9 \mathrm{~Hz}, \mathrm{H}_{\text {arom }}\right), 6.05\left(\mathrm{~d}, 1 \mathrm{H}, J_{1,2}=\right.$ $1.6 \mathrm{~Hz}, \mathrm{H}-1), 5.54\left(\mathrm{~d}, 1 \mathrm{H}, J_{\mathrm{OH}-2,2}=6.0 \mathrm{~Hz}, \mathrm{OH}-2\right), 5.36(\mathrm{~d}, 1 \mathrm{H}$, $\left.J_{\mathrm{OH}-3,3}=4.8 \mathrm{~Hz}, \mathrm{OH}-3\right), 4.91\left(\mathrm{~d}, 1 \mathrm{H}, J_{\mathrm{OH}-5,5}=5.9 \mathrm{~Hz}, \mathrm{OH}-5\right)$, $4.62\left(\mathrm{dd}, 1 \mathrm{H}, J_{\mathrm{OH}-6,6 \mathrm{a}}=6.0 \mathrm{~Hz}, J_{\mathrm{OH}-6,6 \mathrm{~b}}=5.2 \mathrm{~Hz}, \mathrm{OH}-6\right), 4.09$ (m, $1 \mathrm{H}, \mathrm{H}-2), 4.03$ (dd, $\left.1 \mathrm{H}, J_{4,3}=5.9 \mathrm{~Hz}, J_{4,5}=3.1, \mathrm{H}-4\right), 3,99$ $(\mathrm{m}, 1 \mathrm{H}, \mathrm{H}-3), 3.84\left(\mathrm{~s}, 3 \mathrm{H}, \mathrm{OCH}_{3}\right), 3.54(\mathrm{~m}, 1 \mathrm{H}, \mathrm{H}-5), 3.38(\mathrm{~m}$, $2 \mathrm{H}, \mathrm{H}-6) .{ }^{13} \mathrm{C}$ NMR (100 MHz, DMSO- $\left.d_{6}\right) \delta=165.0(\mathrm{C}=\mathrm{O})$, $163.9\left(\mathrm{C}_{\text {arom }}\right), 132.0\left(\mathrm{CH}_{\text {arom }}\right), 122.2\left(\mathrm{C}_{\text {arom }}\right), 114.5\left(\mathrm{CH}_{\text {arom }}\right)$, 102.6 (C-1), 85.6 (C-4), 81.6 (C-2), 77.0 (C-3), 70.9 (C-5), 62.8 (C-6), $56.0\left(\mathrm{OCH}_{3}\right)$. HRMS (ESI): $\mathrm{m} / z=337.0894$ calcd. for $\mathrm{C}_{14} \mathrm{H}_{18} \mathrm{O}_{8} \mathrm{Na}$ : 337.0897.

Phenyl-1-thio- $\beta$-D-galactofuranoside (7): To a solution of 5 (100 $\mathrm{mg}, 0.32 \mathrm{mmol}$ ) in phosphate buffer $50 \mathrm{mM} \mathrm{pH} 8$ (20 $\mathrm{mL}$ ) was added thiophenol $(130 \mu \mathrm{L}, 1.3 \mathrm{mmol})$ followed by the double mutant enzyme CtAraf51 E173A L319V (800 $\mu \mathrm{L}$ at $6 \mathrm{mg} / \mathrm{mL}$ in $50 \mathrm{mM}$ phosphate buffer $\mathrm{pH}$ 7). The $\mathrm{pH}$ of the solution was adjusted to 8 by addition of $\mathrm{NaOH} 2 \mathrm{~N}$. The mixture was then stirred at room temperature for 16 hours. After freeze-drying, the mixture was purified by column chromatography on silica gel (dichloromethane/methanol 9:1) to yield the corresponding product 7 as a white solid with $82 \%$ yield $(71 \mathrm{mg}, 0.26 \mathrm{mmol}) .{ }^{1} \mathrm{H}$ NMR $(400 \mathrm{MHz}$; DMSO- $\left.d_{6}\right) \delta=7.54-7.56\left(\mathrm{~m}, 2 \mathrm{H}, \mathrm{H}_{\text {arom }}\right), 7.33-7.24(\mathrm{~m}, 3 \mathrm{H}$, $\left.\mathrm{H}_{\text {arom }}\right), 5.25\left(\mathrm{~d}, 1 \mathrm{H}, J_{1,2}=5.0 \mathrm{~Hz}, \mathrm{H}-1\right), 4.10\left(\mathrm{dd}, 1 \mathrm{H}, J_{3,4}=7.7\right.$ $\left.\mathrm{Hz}, J_{3,2}=5.3 \mathrm{~Hz}, \mathrm{H}-3\right)$, 4.00-3.96 (m, $\left.2 \mathrm{H}, \mathrm{H}-2, \mathrm{H}-4\right), 3.74(\mathrm{~m}, 1$ $\mathrm{H}, \mathrm{H}-5), 3.62$ (d, $\left.2 \mathrm{H}, J_{6,5}=6.4 \mathrm{~Hz}, \mathrm{H}-6\right) .{ }^{13} \mathrm{C} \mathrm{NMR} \mathrm{(100} \mathrm{MHz,}$ DMSO- $\left.d_{6}\right) \delta=136.3\left(\mathrm{C}_{\text {arom }}\right), 132.9,129,125.1\left(\mathrm{CH}_{\text {arom }}\right), 93.1$ (C-1), 83.2 (C-4), 83.1 (C-2), 77.8 (C-3), 72.0 (C-5), 64.5 (C-6). HRMS (ESI): $m / z=295.0634$ calcd. for $\mathrm{C}_{12} \mathrm{H}_{16} \mathrm{O}_{5} \mathrm{SNa}$ : 295.0616.

\section{Conflicts of interest}

There are no conflicts to declare.

\section{Acknowledgements}

We are grateful to CNRS and the "Ministère de l'enseignement supérieur et de la recherche" for financial support. This work benefited from the support of the project C-linkAse ANR-15-CE07-0009-01 of the French National Research Agency (ANR). The authors are also grateful to the GlycoOuest network, supported by the Région Bretagne and the Région Pays de la Loire.

\section{Notes and references}

1. P. C. Collins and R. J. Ferrier, Monosaccharides: Their chemistry and their roles in natural products, Wiley, New York, 1995.

2. P. Peltier, R. Euzen, R. Daniellou, C. Nugier-Chauvin and V. Ferrieres, Carbohydrate research, 2008, 343, 1897-1923.

3. P. J. Brennan and H. Nikaido, Annual Review of Biochemistry, 1995, 64, 29-63.

4. R. M. de Lederkremer and W. Colli, Glycobiology, 1995, 5, 547-552.

5. S. J. Turco, P. A. Orlandi, S. W. Homans, M. A. Ferguson, R. A. Dwek and T. W. Rademacher, Journal of Biological Chemistry, 1989, 264, 6711-6715.

6. J.-P. Latge, Medical Mycology, 2009, 47, S104-S109.

7. L. Legentil, J.-L. Audic, R. Daniellou, C. Nugier-Chauvin and V. Ferrières, Carbohydrate research, 2011, 346, 1541-1545.

8. M. Suleman, J. P. Gangneux, L. Legentil, S. Belaz, Y. Cabezas, C. Manuel, R. Dureau, O. Sergent, A. Burel, F. Daligault, V. Ferrieres and F. Robert-Gangneux, Antimicrob Agents Chemother, 2014, 58, 2156-2166.

9. C. B. Davis, R. D. Hartnell, P. D. Madge, D. J. Owen, R. J. Thomson, A. K. J. Chong, R. L. Coppel and M. v. Itzstein, Carbohydrate research, 2007, 342, 1773-1780.

10. V. Ferrières, J.-N. Bertho and D. Plusquellec, Carbohydrate research, 1998, 311, 25-35.

11. R. Dureau, M. Gicquel, I. Artur, J.-P. Guégan, B. Carboni, V. Ferrières, F. Berrée and L. Legentil, Organic \& Biomolecular Chemistry, 2015, 13, 4940-4952.

12. L. Baldoni and C. Marino, Carbohydrate research, 2012, 362, 70-78.

13. F. Marco and M. Marzia, Current Organic Chemistry, 2013, 17, 701-718.

14. P. M. Danby and S. G. Withers, ACS Chemical Biology, 2016, 11, 1784-1794.

15. M. Rietschel-Berst, N. H. Jentoft, P. D. Rick, C. Pletcher, F. Fang and J. E. Gander, The Journal of biological chemistry, 1977, 252, 3219-3226.

16. L. S. Daley and G. A. Strobel, Plant Science Letters, 1983, 30, 145-154.

17. N. Ramli, M. Fujinaga, M. Tabuchi, K. Takegawa and S. Iwahara, Bioscience, biotechnology, and biochemistry, 1995, 59, 1856-1860.

18. G. L. Wallis, F. W. Hemming and J. F. Peberdy, Biochimica et biophysica acta, 2001, 1525, 19-28.

19. E. Matsunaga, Y. Higuchi, K. Mori, N. Yairo, T. Oka, S. Shinozuka, K. Tashiro, M. Izumi, S. Kuhara and K. Takegawa, PLOS ONE, 2015, 10, e0137230. 

T. Oka, K. Tashiro and K. Takegawa, Bioscience, biotechnology, and biochemistry, 2017, 81, 1314-1319.

21. M. T. Numan and N. B. Bhosle, J Ind Microbiol Biotechnol, 2006, 33, 247-260.

22. A. Pennec, R. Daniellou, P. Loyer, C. Nugier-Chauvin and V. Ferrieres, Carbohydrate research, 2015, 402, 50-55.

23. I. Chlubnova, D. Filipp, V. Spiwok, H. Dvorakova, R. Daniellou, C. Nugier-Chauvin, B. Kralova and V. Ferrieres, Org Biomol Chem, 2010, 8, 2092-2102.

24. M. Almendros, D. Danalev, M. Francois-Heude, P. Loyer, L. Legentil, C. Nugier-Chauvin, R. Daniellou and V. Ferrieres, Org Biomol Chem, 2011, 9, 8371-8378.

25. Q. Pavic, S. Tranchimand, L. Lemiegre and L. Legentil, Chem Commun (Camb), 2018, 54, 5550-5553.

26. I. Chlubnová, PhD thesis, Rennes 1 University, 2010.

27. E. J. Taylor, N. L. Smith, J. P. Turkenburg, S. D'Souza, H. J. Gilbert and G. J. Davies, Biochem J, 2006, 395, 31-37.

28. O. Trott and A. J. Olson, J Comput Chem, 2010, 31, 455-461.

29. E. Krieger and G. Vriend, Bioinformatics, 2014, 30, 2981-2982.

30. W. M. Patrick, A. E. Firth and J. M. Blackburn, Protein Engineering Design and Selection, 2003, 16, 451-457.

31. F. W. Studier, Protein Expression and Purification, 2005, 41, 207-234.

32. R. Euzen, V. Ferrieres and D. Plusquellec, J Org Chem, 2005, 70, 847-855.

33. P. Peltier, R. Daniellou, C. Nugier-Chauvin and V. Ferrieres, Org Lett, 2007, 9, 5227-5230.

34. E. Krieger, T. Darden, S. B. Nabuurs, A. Finkelstein and G. Vriend, Proteins, 2004, 57, 678-683.

35. M. Di Pierro, R. Elber and B. Leimkuhler, J Chem Theory Comput, 2015, 11, 5624-5637.

36. K. N. Kirschner, A. B. Yongye, S. M. Tschampel, J. Gonzalez-Outeirino, C. R. Daniels, B. L. Foley and R. J. Woods, J Comput Chem, 2008, 29, 622-655.

37. A. D. Becke, The Journal of Chemical Physics, 1993, 98, 5648-5652.

38. C. Lee, W. Yang and R. G. Parr, Physical Review B, 1988, 37, 785-789.

39. M. J. Frisch, G. W. Trucks, H. B. Schlegel, G. E. Scuseria, M. A. Robb, J. R. Cheeseman, G. Scalmani, V. Barone, G. A. Petersson, H. Nakatsuji, X. Li, M. Caricato, A. V. Marenich, J. Bloino, B. G. Janesko, R. Gomperts, B. Mennucci, H. P. Hratchian, J. V. Ortiz, A. F. Izmaylov, J. L. Sonnenberg, Williams, F. Ding, F. Lipparini, F. Egidi, J. Goings, B. Peng, A. Petrone, T. Henderson, D. Ranasinghe, V. G. Zakrzewski, J. Gao, N. Rega, G. Zheng, W. Liang, M. Hada, M. Ehara, K. Toyota, R. Fukuda, J. Hasegawa, M. Ishida, T. Nakajima, Y. Honda, O. Kitao, H. Nakai, T. Vreven, K. Throssell, J. A. Montgomery Jr., J. E. Peralta, F. Ogliaro, M. J. Bearpark, J. J. Heyd, E. N. Brothers, K. N. Kudin, V. N. Staroverov, T. A. Keith, R. Kobayashi, J. Normand, K. Raghavachari, A. P. Rendell, J. C. Burant, S. S. Iyengar, J. Tomasi, M. Cossi, J. M. Millam, M. Klene, C. Adamo, R. Cammi, J. W. Ochterski, R. L. Martin, K. Morokuma, O. Farkas, J. B. Foresman and D. J. Fox, Journal, 2016. Lee and L. G. Pedersen, The Journal of Chemical Physics, 1995, 103, 8577-8593. 